\title{
The Arden grating acuity: effect of age and optical factors in the normal patient, with prediction of the false negative rate in screening for glaucoma
}

\author{
HARDEEP SINGH, R. L.COOPER, V. A. ALDER, G. J. CRAWFORD, A. TERRELL, AND \\ I. J. CONSTABLE
}

From the University Department of Ophthalmology, Perth, Western Australia

SUMmary The Arden contrast sensitivity was investigated in normal persons, cataract eyes, and glaucoma patients with only plates 6 and 7 of the Arden grating set. The mean score of 90 normal eyes on plate 6 was $9 \cdot 50 \pm 2 \cdot 29$ and on plate 7 it was $9 \cdot 44 \pm 2 \cdot 32$. The mean scores of patients with early cataract were $14.51 \pm 2.99$ on plate 6 and $13 \cdot 74 \pm 3.26$ on plate 7 . Several patients with cataract missed the grating on plate 7 . Mydriasis and miosis did not affect contrast sensitivity in normal eyes. Mydriasis significantly improved contrast sensitivity in patients with early cataract. In patients with glaucoma enlargement of the pupil from a miotic state to near normal size significantly improved contrast sensitivity. It is predicted that if plates 6 and 7 are used in mass screening for glaucoma in the elderly, there will be a false negative rate of $83 \%$ for plate 6 and $52 \%$ for plate 7 . A false positive rate of $17 \%$ is predicted.

Contrast sensitivity has been shown to be reduced in glaucoma subjects, whether when tested with printed sinusoidal grating plates designed by Arden $^{1}$ or with electronically generated sinusoidal grating patterns ${ }^{2}$ even when distant optotype acuity was normal. The plates are simple to use, even by lay personnel, and would thus be a potentially valuable tool for use in mass screenings for glaucoma. This was first suggested by Arden and Jacobsen ${ }^{3}$ and has been carried out in Western Australia with the 2 highest frequency plates. ${ }^{4}$

Several other factors in elderly glaucoma patients which may affect contrast sensitivity, for example, age,${ }^{5}$ cataract, ${ }^{6}$ macular disease, ${ }^{78}$ and pupil size, ${ }^{9}$ have to be considered before the scores of glaucoma subjects on Arden plates can be standardised and thus be of value in mass screenings for glaucoma.

We investigated the effect of age and cataracts in nonglaucomatous persons and of pupil size in normal persons and glaucoma patients. By comparing glaucoma patients with normal sized pupils with an age- and disease-matched sample we attempted to predict the false negative rate for mass screening for glaucoma using printed Arden grating plates numbers 6 and 7.

Correspondence to Dr R L Cooper, Department of Ophthalmology. Royal Perth Hospital, GPO Box X2213, Perth 6001. Western Australia.

\section{Subjects and methods}

Plates 6 and 7 of the Arden grating set subtending 3.2 and 6.4 cycles/degree respectively at $57 \mathrm{~cm}$ were used in this investigation. Plate 4 was used for demonstration purposes only and its score was not used in the final analysis. The technique was similar to that described by Arden. ${ }^{3}$ Near correction was worn for all tests. Ambient room light varied between 18 and 90 lux measured at the chart. This was supplemented by a 60 watt frosted bulb situated at exactly $1 \mathrm{~m}$ from the printed plates (120 lux). The reflected luminance of the chart surface was $20 \mathrm{~cd} \mathrm{~m}^{-2}$ for the bulb alone. The original Arden set was used for testing the glaucoma patients, but 2 sets of photographic copies of the plates were used for normal population testing. (The copies were tested against the original set by 2-way analysis of variance for 3 subjects aged 20,33, and 54. No significant difference between scores of the subjects and between the original prints and the copies were detected for the first 3 readings for each plate. For the fourth and fifth readings an improvement in scores occurred, which were significantly different from the first 3.) The scores were first determined for one eye on plates 4,6 , and 7 , and then for the other eye. Each eye was tested 3 times. The mean of the 3 scores was used as the Arden score for 
each plate. No score was assigned if a subject did not see the grating. The results were analysed separately for plates 6 and 7 .

The effects of miosis and mydriasis were studied on volunteers from the normal, cataract, and glaucoma groups. Pilocarpine 2\% was used for miosis and phenylephrine $10 \%$ for mydriasis, except for the glaucoma patients, who were instructed to stop miotics for 24 hours before their second visit, which was 2 to 4 weeks later. All subjects thus acted as their own controls.

Normal subjects (Table 1) were chosen from hospital volunteers and relatives of patients. There was a total of 90 subjects, with ages ranging from 10 to 84 years (mean 38.9 years). There were 36 males and 54 females. All had normal eyes, with corrected vision $6 / 6$ N6 or better. None had retinal or macular disease.

Subjects with minimal cataract (Table 2) were 27 in number, with age range 53 to 82 years (mean 70.9 years). Distant vision was $6 / 18$ or better and near vision N8 or better. All fundi were normal.

Twenty-five patients ( 45 eyes) with well documented chronic simple glaucoma were selected to study the effect of miosis on Arden grating acuity. All patients had pathologically cupped discs, arcuate field defects of varying severity, and applanation tonometry readings of more than $21 \mathrm{mmHg}$ at diagnosis. All patients were on antiglaucoma therapy which included miotic drops (pilocarpine or carbachol). Their age and sex distributions are shown in Table 3. Distant visual acuity was $6 / 18$ or better in 41 eyes. The 4 remaining eyes had visual acuities of $6 / 36$. Near visual acuity was N8 or better in all eyes. Early lens opacities were present in 35 eyes. One patient had drusen in both eyes, and another was a diabetic with a few hard exudates scattered in the fundus. Both had normal visual acuity. None had macular disease.

Twenty-three patients ( 42 eyes) from the glaucoma group were selected for comparison of Arden contrast sensitivity in glaucomatous persons with that of non-glaucomatous persons matched for age, visual acuity, and early cataract. Table 4 shows the age and sex distributions for both these groups and Table 5 compares their clinical characteristics.

\section{Results}

Contrast sensitivity in normal subjects and effect of age. Since there was no significant difference in scores between the right and left eyes both for plates 6 $(\mathrm{p}=0.72$, paired $t$ test $)$ and $7(\mathrm{p}=0.39$, paired $t$ test $)$, one eye per subject was selected randomly for the study. The mean score of 90 eyes from 90 normal subjects was $9 \cdot 50 \pm 2 \cdot 29$ on plate 6 and $9 \cdot 44 \pm 2 \cdot 32$ on
Table 1 Age and sex distribution of normal subjects

\begin{tabular}{lccc}
\hline Age (years) & Male & Female & Total \\
\hline $10-19$ & 6 & 6 & 12 \\
$20-29$ & 5 & 18 & 23 \\
$30-39$ & 12 & 5 & 17 \\
$40-49$ & 2 & 7 & 9 \\
$50-59$ & 7 & 10 & 17 \\
$60-69$ & 1 & 5 & 6 \\
$70-79$ & 3 & 2 & 5 \\
$80-89$ & 0 & 1 & 1 \\
Total & 36 & 54 & 90 \\
\hline
\end{tabular}

Table 2 Age and sex distribution of subjects with early cataracts

\begin{tabular}{lccc}
\hline Age (years) & Male & Female & Total \\
\hline $50-59$ & 2 & 2 & 4 \\
$60-69$ & 0 & 6 & 6 \\
$70-79$ & 3 & 11 & 14 \\
$80-89$ & 3 & 0 & 3 \\
Total & 8 & 19 & 27 \\
\hline
\end{tabular}

Table 3 Age and sex distribution of glaucoma patients

\begin{tabular}{llcc}
\hline Age (years) & Male & Female & Total \\
\hline $40-49$ & - & 1 & 1 \\
$50-59$ & - & - & - \\
$60-69$ & 2 & 4 & 6 \\
$70-79$ & 9 & 3 & 13 \\
$80-89$ & 1 & 1 & 1 \\
$90-99$ & - & 13 & 25 \\
Total & 12 & & \\
\hline
\end{tabular}

Table 4 Age and sex distribution of glaucoma patients and clinically matched nonglaucomatous subjects

\begin{tabular}{|c|c|c|c|c|c|c|}
\hline \multirow{2}{*}{$\begin{array}{l}\text { Age } \\
\text { (years) }\end{array}$} & \multicolumn{3}{|c|}{ Glaucoma } & \multicolumn{3}{|c|}{ Normals } \\
\hline & Male & Female & Total & Male & Female & Total \\
\hline $60-69$ & 2 & 4 & 6 & 1 & 5 & 6 \\
\hline $70-79$ & 9 & 4 & 13 & 5 & 9 & 14 \\
\hline $80-89$ & 1 & 3 & 4 & 3 & 1 & 4 \\
\hline Total & 12 & 11 & 23 & 9 & 15 & 24 \\
\hline
\end{tabular}

Table 5 Characteristics of glaucoma patients with clinically matched nonglaucomatous subjects

\begin{tabular}{lll}
\hline Characteristics & Glaucoma patients & Matched sample \\
\hline No. of subjects & 23 & 24 \\
No. of eyes & 42 & 48 \\
Mean age (years) & $74 \cdot 43$ & $73 \cdot 88$ \\
VA 6/18 or better & 38 & 48 \\
VA 6/36 & 4 & 0 \\
VA (near) N8 or better & 42 & 48 \\
Presence of lens opacities & 33 & 29 \\
Presence of drusen & 2 & 2 \\
Macular disease & None & None \\
\hline
\end{tabular}


Fig. 1 Histogram of scores on Arden plate 6 ( 90 eyes of 90 normal subjects).
Fig. 2 Histogram of scores on Arden plate 7 (90 eyes of 90 normal subjects).

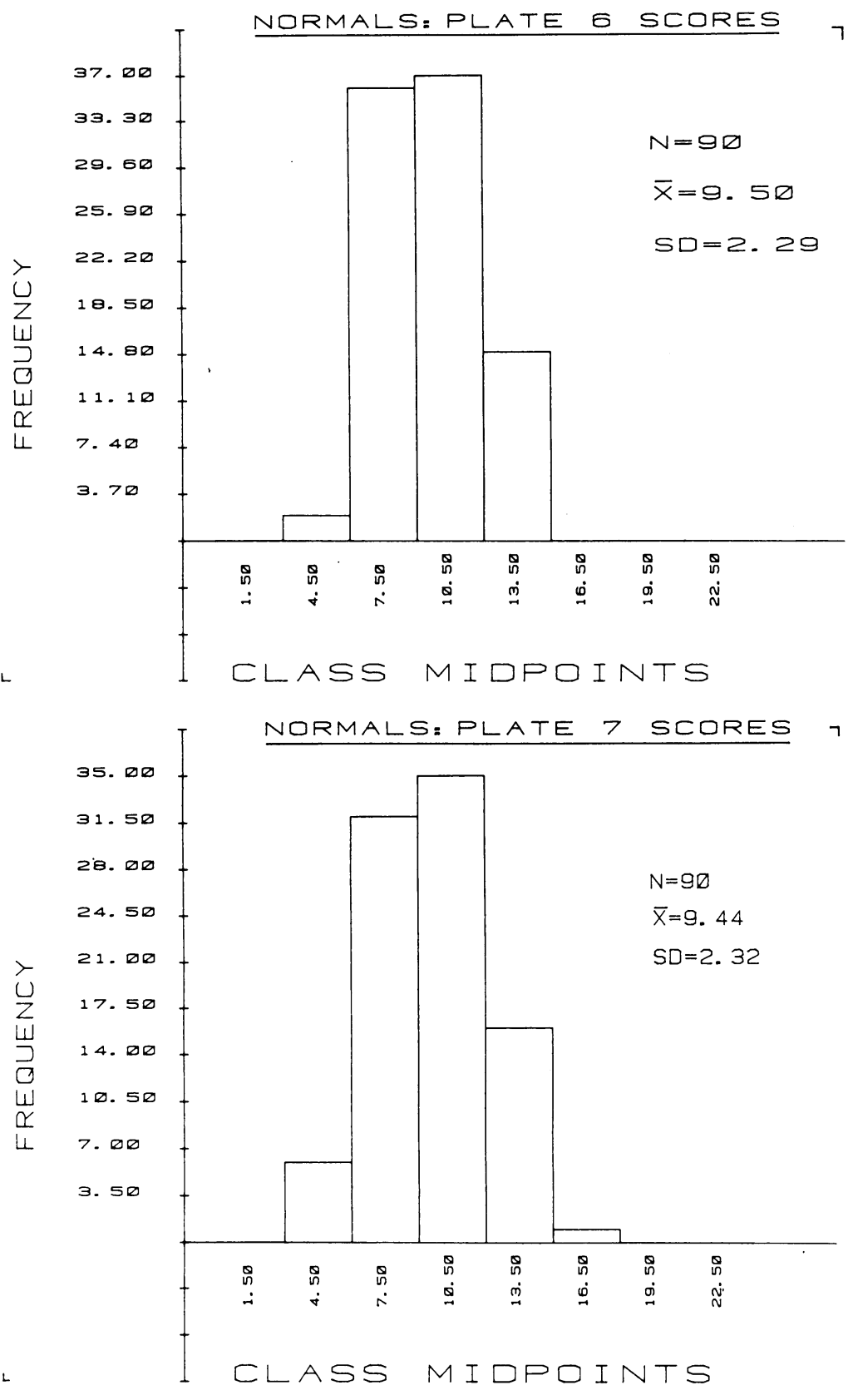

plate 7 (Figs. 1 and 2). The effect of age on contrast sensitivity is shown in scattergraphs (Figs. 3 and 4). A wide variation of scores was found for the whole age range, for both plates 6 and 7 . There was a very slight increase of scores with age, especially after the sixth decade, that is, contrast sensitivity worsened with age.
Contrast sensitivity in subjects with early cataracts. This was studied in 48 eyes of 27 subjects. The mean score on plate 6 was $14.51 \pm 2.99$. All eyes saw the grating. For plate 7,33 eyes saw the grating pattern (mean score $13 \cdot 74 \pm 3 \cdot 26$ ) while 15 eyes $(31 \cdot 6 \%)$ missed it. Table 6 shows the optotype visual acuity of the subjects who missed plate 7 . 


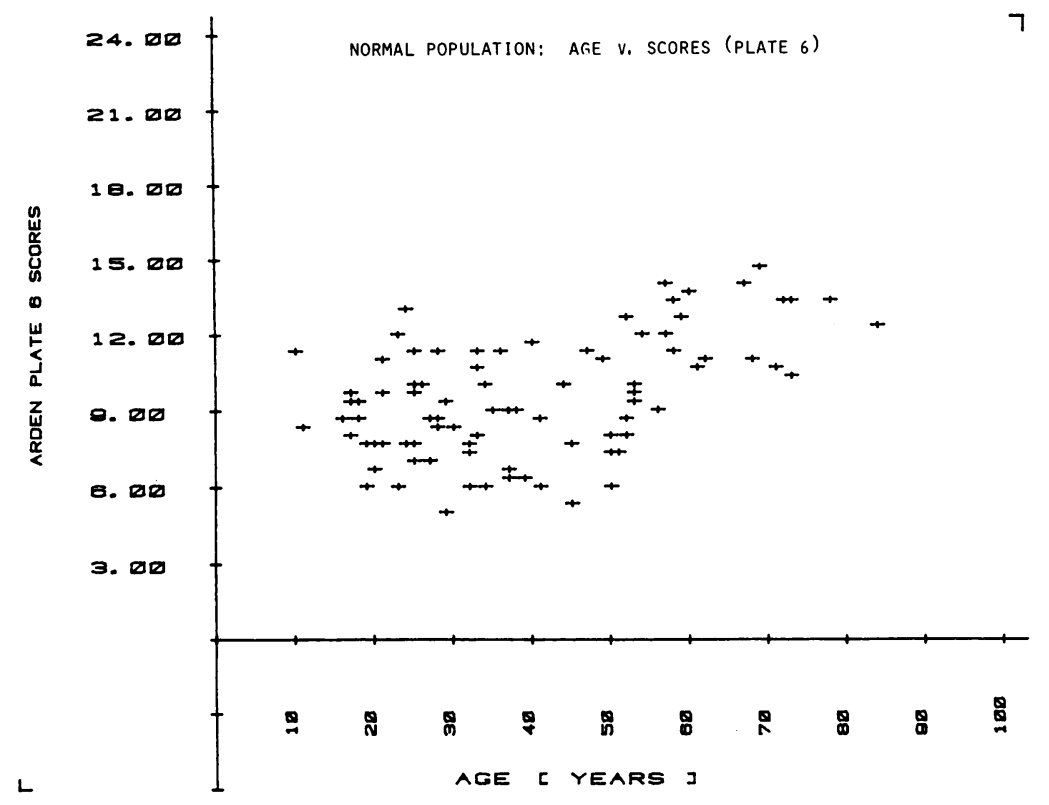

Fig. 3 Scattergraph of plate 6 scores versus age $(90$ eyes of 90 normal subjects).

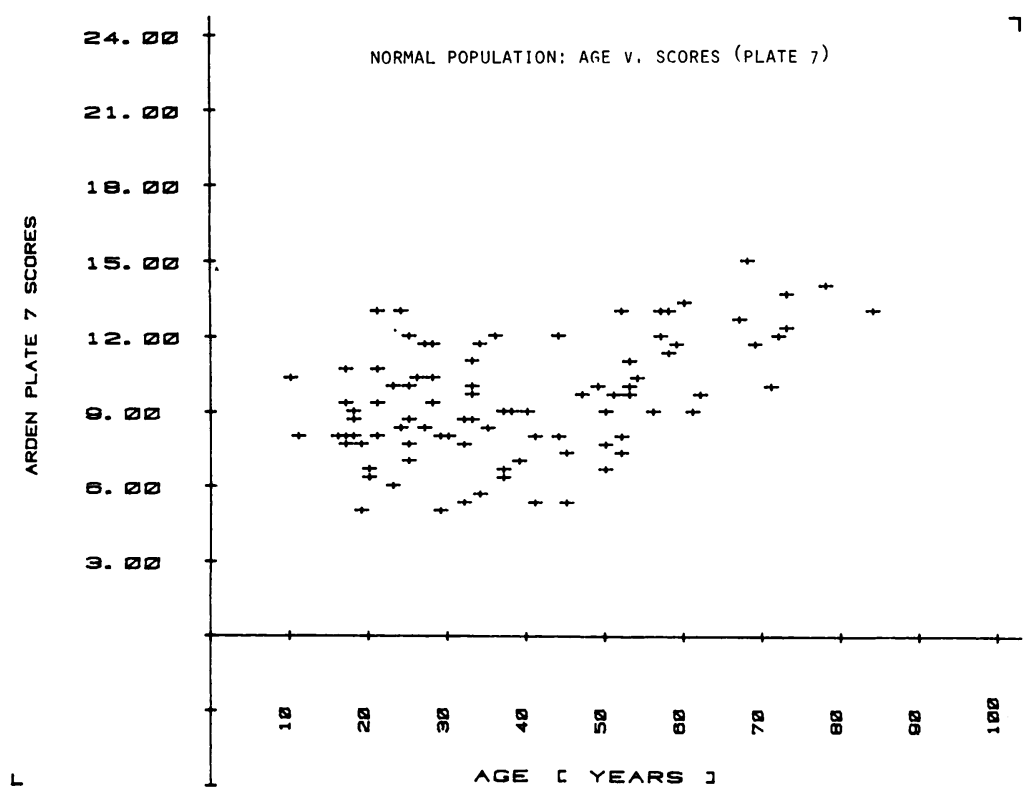

Fig. 4 Scattergraph of plate 7 scores versus age (90 eyes of 90 normal subjects).

Comparison of contrast sensitivity between subjects with early cataract and an age-matched normal population. The performance on plates 6 and 7 of 22 eyes with early cataract from 12 subjects (mean age 70.42 years) was compared with that of 22 eyes of 11 normal subjects (mean age 70.73 years). The pupils were normal sized in both groups.
The mean score for plate 6 of the cataract group $(14 \cdot 41 \pm 3 \cdot 21)$ was significantly different from that of normal subjects $(12 \cdot 24 \pm 1 \cdot 44)(\mathrm{p}=0 \cdot 003$, unpaired $t$ test). For plate 7, 9 eyes $(41 \%)$ with cataract missed the grating, whereas none of the normal eyes did. Mean score of the 13 eyes with cataract which saw the plate $(12 \cdot 87 \pm 3 \cdot 67)$ was not statistically different 
Table 6 Optotype acuity of the subjects with early cataract who missed the grating on plate 7

\begin{tabular}{llll}
\hline $\begin{array}{l}\text { Distant } \\
\text { acuity }\end{array}$ & $\begin{array}{l}\text { Number } \\
\text { of eyes }\end{array}$ & $\begin{array}{l}\text { Near } \\
\text { acuity }\end{array}$ & $\begin{array}{l}\text { Number } \\
\text { of eyes }\end{array}$ \\
\hline $6 / 6$ & 1 & N4.5 & 4 \\
$6 / 9$ & 7 & N5 & 5 \\
$6 / 12$ & 4 & N6 & 3 \\
$6 / 18$ & 3 & N8 & 3 \\
Total & 15 & Total & 15 \\
\hline
\end{tabular}

from the scores of the normal eyes $(12 \cdot 17 \pm 1 \cdot 78)(\mathrm{p}=$ $0 \cdot 22$, unpaired $t$ test).

Effect of mydriasis on contrast sensitivity. This was studied in 16 eyes of normal subjects (age range 50 to 84 years) and 34 eyes with early cataract (age range 53 to 82 years). No attempt was made to age-match these groups.

For the 16 normal eyes there was no difference in scores before and after dilatation, both for plate 6 $(\mathrm{p}=0.46$, paired $t$ test $)$ and plate $7(\mathrm{p}=0.74$, paired $t$ test). For the 34 eyes with early cataract, however, there was a significant improvement in scores on plate 6 after dilatation ( $\mathrm{p}=0 \cdot 0003$, paired $t$ test). On plate 7 only 22 eyes saw the grating, whereas 12 eyes (35\%) missed it. The scores were significantly better in the 22 eyes when they were dilated $(\mathrm{p}=0.04$, paired $t$ test). Moreover, with dilatation 4 eyes of the 12 that originally missed the plate were now able to see the grating (that is, 8 , or $24 \%$, still could not see plate 7 ).

Effect of miosis on normal persons. This was studied in 11 eyes of 11 volunteers (age range 22 to 52 years, visual acuities $6 / 6, \mathrm{~N} 5$ in all). There was no significant difference in scores before and after miosis for both plates $6(\mathrm{p}=0.89$, paired $t$ test $)$ and $7(\mathrm{p}=$ $0 \cdot 85$, paired $t$ test), though there was a tendency for scores to worsen.

Effect of miosis on a glaucoma population. Of the 45 eyes $26(58 \%)$ could see the grating on plate 6 in the miotic state, while 19 eyes $(42 \%)$ could not. The mean score of the 26 eyes in the miotic state $(15 \cdot 65 \pm 2 \cdot 61)$ was significantly different from the mean score of these same eyes when the pupils were normal sized $(3 \mathrm{~mm})(13.37 \pm 3.43),(\mathrm{p}=0.00008$, paired $t$ test). Eleven (24\%) of the 19 eyes were able to see the grating when the pupils became normal sized. Eight eyes $(19 \%)$ still missed the grating pattern despite having normal sized pupils.

With plate 7 only 10 eyes $(22 \%)$ saw the grating, while 35 eyes $(78 \%)$ could not do so in the miotic state. The mean score of the 10 eyes in the miotic state $(14 \cdot 00 \pm 1 \cdot 10)$ was significantly different from the score of these same eyes when the pupils became normal sized $(12 \cdot 24 \pm 2 \cdot 65)(\mathrm{p}=0 \cdot 008$, paired $t$ test $)$.
Of the 35 eyes which initially missed the pattern 12 $(34 \%)$ were able to see the grating upon enlargement of the pupil. Twenty-three eyes $(57 \%)$ still missed the grating.

Comparison between a glaucoma sample with normal pupils and a matched nonglaucomatous population. Thirty-five eyes $(83 \%)$ of glaucoma subjects with normal sized pupils saw plate 6 , whereas seven eyes (17\%) could not. All the matched population saw the plate. The mean score for those seeing this plate in the glaucoma sample $(13.92 \pm 3.43)$ was not statistically different from that of the matched population $(13 \cdot 11 \pm 2 \cdot 62)(\mathrm{p}=0 \cdot 115)$, unpaired $t$ test $)$.

For plate 7,22 eyes $(52 \%)$ of glaucoma subjects with normal pupils saw the grating while 20 eyes $(48 \%)$ could not. In the matched population 40 eyes (83\%) saw the grating, while 8 eyes $(17 \%)$ did not. The mean score on this plate of the glaucoma group $(12 \cdot 86 \pm 3.07)$ was not significantly different from that of the matched population $(12 \cdot 65 \pm 2 \cdot 83)(p=0.390$, unpaired $t$ test).

\section{Discussion}

In contrast to others ${ }^{15}$ we found a small increase in scores for plates 6 and 7 with age, specifically above the fifth decade. Our normal scores and their standard deviations were within the limits originally reported. ${ }^{3}$ This implies that illuminance is probably not critical. Arden's original figure for 'illumination' is stated in terms of luminance. His figures of $130-150 \mathrm{~cd} / \mathrm{m}^{2}$ are 6 to 7 times the value we measured using one 60 watt frosted bulb alone at $1 \mathrm{~m}$, without taking background illuminance into account. Our photographic copies of the original plates purchased from the Institute of Ophthalmology did not introduce a significant variation.

Early cataract with good optotype vision for near resulted in a significant reduction in contrast sensitivity. This is thought to be due to light scatter and glare. ${ }^{6}$ It is difficult to explain why some eyes did not see plate 7 . One explanation is that there is a bimodal distribution of scores for cataract patients with 2 groups that we could not fully characterise. This observation has important implications for the separation of glaucoma suspects or patients from the aged population who are at risk.

In order to define the thresholds of plates 6 and 7 for the glaucomatous eye, before diagnosis or treatment, i.e., with no miosis, we examined the effect of variations of pupil size on the Arden acuity. Mydriasis of eyes with early cataract, but good near optotype acuity, improved contrast sensitivity. The same happened when glaucoma patients stopped miotics. (Pupil size for the dilated normal eyes and in early cataract patient was $4 \mathrm{~mm}$ or more, while for the 


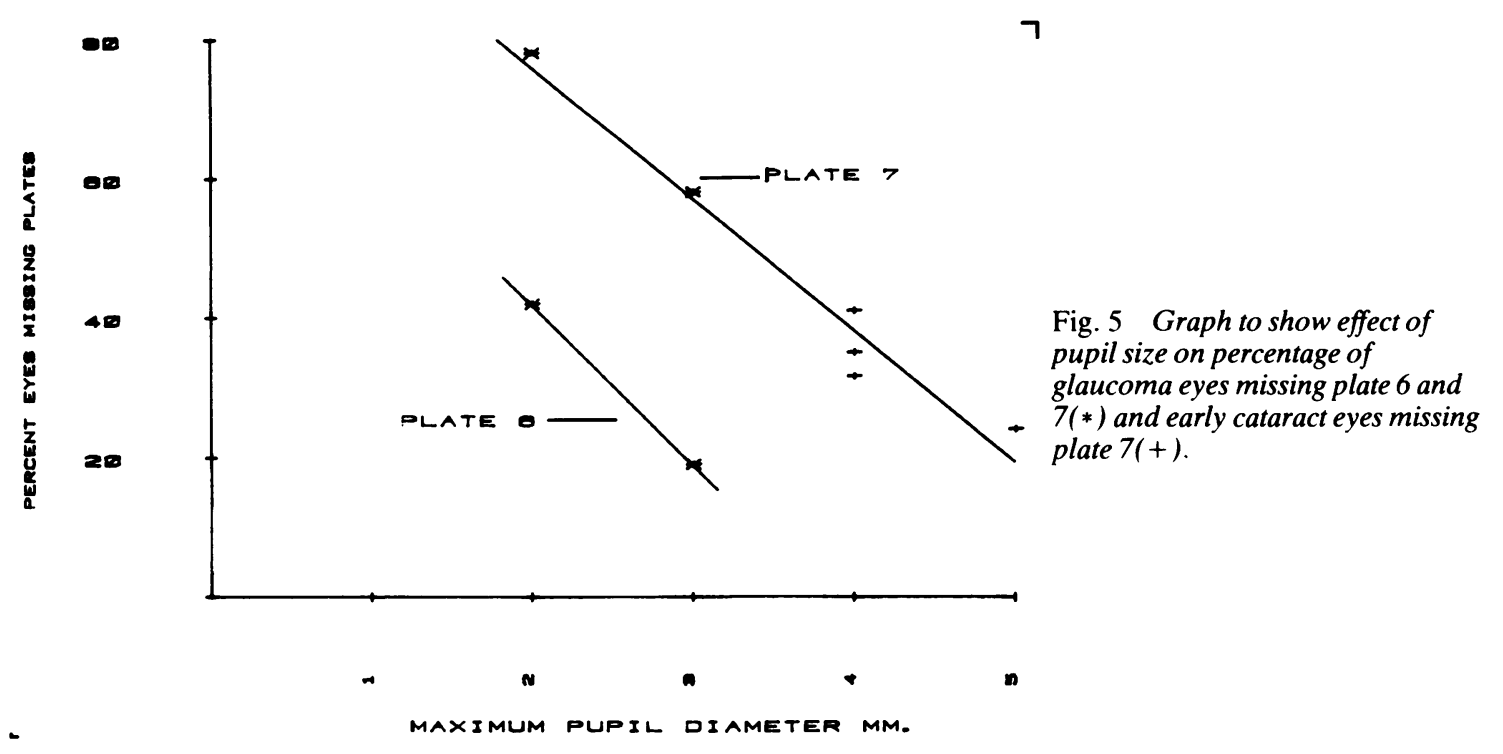

nonmiotic glaucoma eyes it rarely exceeded $3.5 \mathrm{~mm}$.) These changes may be due to the exposure of more optically homogeneous areas of the lens, thus decreasing scatter and improving contrast sensitivity. We could not statistically examine the types of lens opacities because of the small samples.

It could be argued that familiarisation would account for score improvement. This may have occurred in mydriasis for the cataract group, but the normal persons whose eyes were dilated or miosed under identical testing conditions showed no significant change in scores. Miosis in the normal persons tended to be associated 'with worse scores. The glaucoma group had 2 to 4 weeks between tests. Under similar conditions for glaucoma patients in follow-up no significant changes in scores have been noted (unpublished data).

In some eyes with lens opacities plate 7 gratings were not seen at all. This is in agreement with $\mathrm{Arden}^{3}$ for glaucoma patients. For those eyes which could see plate 7 the scores did not differ from age-matched normals, or controls matched for visual acuity or pathological condition (Table 5). This again implies the presence of 2 separate groups or inadequate matching for statistical purposes. However, this pattern occurred for the glaucoma group even with plate 6 . When the percentages of eyes which missed plate 6 or 7 are plotted against mean pupil diameters, however, a simple inverse relationship is evident (Fig. $5)$. This implies that for some patients with early lens opacities and/or glaucoma the contrast sensitivity threshold is not attained for either plate, and that this is due to pupil size. These findings appear to con- tradict previous reports for glaucoma. ${ }^{23}$ In the normal subjects we found no effect of pupil size on Arden grating scores, as did Arden and Jacobsen. ${ }^{3}$

Unfortunately we may not be able to separate the effects of field loss from lens opacities with these data, because the patients who had stopped miotics did not quite attain normal pupil size. If, however, it is assumed that their pupils did attain normal size, a prediction of false negative rate can be made only from the number of eyes which missed the plates, because those eyes which saw the plates did not have significantly different scores from their matched controls.

Table 7 Characteristics of glaucomatous eyes which missed the gratings in the miotic state but were able to see the pattern when the pupils became normal sized (11 eyes on plate 6 and 12 eyes on plate 7)

\begin{tabular}{llll}
\hline Characteristics & & $\begin{array}{l}\text { Plate } 6 \\
\text { (Il eyes) }\end{array}$ & $\begin{array}{l}\text { Plate } 7 \\
\text { (I2 eves) }\end{array}$ \\
\hline Distant vision & $6 / 6$ & - & 2 \\
& $6 / 9$ & 6 & 4 \\
& $6 / 12$ & 3 & 4 \\
& $6 / 18$ & 2 & 1 \\
Near vision & $6 / 36$ & - & 1 \\
& N4.5 & 2 & 1 \\
& N5 & 6 & 9 \\
Field loss & N6 & - & 1 \\
& N8 & 3 & 1 \\
& Early & 3 & 4 \\
Lens opacities & Moderate & 4 & 5 \\
& Advanced & 4 & 3 \\
& Absent & 2 & 3 \\
& Nucleosclerosis & 1 & 2 \\
\hline
\end{tabular}


Table 8 Characteristics of glaucoma eyes that missed plate 6 ( 7 eyes) and 7 (20 eyes) with the pupils normal sized

\begin{tabular}{llll}
\hline Characteristics & & $\begin{array}{l}\text { Plate 6 } \\
\text { (7 eyes) }\end{array}$ & $\begin{array}{l}\text { Plate } 7 \\
\text { (20 eyes) }\end{array}$ \\
\hline Distant vision & $6 / 6$ & 1 & 1 \\
& $6 / 9$ & 2 & 7 \\
& $6 / 12$ & 1 & 6 \\
& $6 / 18$ & 2 & 3 \\
Near vision & $6 / 36$ & 1 & 3 \\
& N4·5 & - & 4 \\
Field loss & N5 & 2 & 7 \\
& N6 & 3 & 3 \\
& N8 & 3 & 6 \\
Lens opacities & Early & 1 & 8 \\
& Moderate & 3 & 7 \\
& Advanced & - & 5 \\
& Absent & 2 & 2 \\
& Nucleosclerosis & 5 & 8 \\
& Mild cortical & 5 & 10 \\
\hline
\end{tabular}

Glaucomatous eyes which missed the plates when miotic but could see them on enlargement (Table 7) did not appear to differ from the eyes which still missed the plates (Table 8), except for the proportions of cataracts. All the matched controls who missed plate 7 had early cataract (Table 9). This means that there may be an effect of glaucoma on the scores, but its contribution cannot be great.

The false negative rate in a glaucoma screening, given that missed plates may indicate damage due to glaucoma, is $83 \%$ for plate 6 and $52 \%$ for plate 7 . From the control group matched for acuity and lens opacities a false positive rate of $17 \%$ is predicted. However, if the effect of pupil size is as great as we have shown, our glaucoma group, who probably did not reach normal pupil size, may not represent the true picture for glaucoma against which to calibrate the test. If this is so, we may have overestimated the false negative rate. We therefore conclude that our modification of the Arden grating test, using the most sensitive plates for this disease, is not a reliable method for screening for glaucoma. If it is combined with tonometry, some additional cases of glaucoma with normal tensions might be detected. But the probability of this is low.
Table 9 Characteristics of matched 'normal' eyes that missed plate 7. All of these eyes were able to see plate 6

\begin{tabular}{lll}
\hline Characteristics & & $\begin{array}{l}\text { Plate } 7 \\
\text { (8 eyes) }\end{array}$ \\
\hline Distant vision & $6 / 6$ & 1 \\
& $6 / 9$ & 3 \\
& $6 / 12$ & 2 \\
Near vision & $6 / 18$ & 2 \\
& N4·5 & 2 \\
& N5 & 2 \\
Lens opacities & N8 & 3 \\
& Nucleoscleorisis & 1 \\
& Mild cortical & 3 \\
\hline
\end{tabular}

We thank Ms Helen Deady for secretarial work and Sisters Murphy and Lockwood for their pleasant co-operation. The original Arden grating test plates were purchased from the Institute of Ophthalmology, Judd Street, London.

The work done by Hardeep Singh was during his tenure as Glaucoma Fellow in University Department of Ophthalmology. Royal Perth Hospital.

\section{References}

1 Arden GB. The importance of measuring contrast sensitivity in cases of visual disturbance. Br J Ophthalmol 1978; 62: 198-209.

2 Atkin A, Bodis-Wollner I, Wolkstein M, Moss A, Podos SM. Abnormalities of central contrast sensitivity in glaucoma. Am J Ophthalmol 1979; 88: 205-11.

3 Arden GB, Jacobsen JJ. A simple grating test for contrast sensitivity: preliminary results indicate value in screening for glaucoma. Invest Ophthalmol Visual Sci 1978: 17: 23-32.

4 Cooper RL. Constable IJ. Terrell A. Mass screening for glaucoma and other eye disease using the Arden grating test. Aust $J$ Ophthalmol 1980: 8: 131-7.

5 Skalka HW. Effect of age on Arden grating acuity. Br J Ophthalmol 1980; 64: 21-3.

6 Hess R. Woo G. Vision through cataracts. Invest Ophthalmol Visual Sci 1978; 17: 428-35.

7 Sjostrand J. Frisen L. Contrast sensitivity in macular disease. Acta Ophthalmol (Kbh) 1977; 55: 507-14.

8 Gucukoglu A. Arden GB. Low frequency contrast sensitivity is lost very early in macular disease. Abstract ARVO Symposium. Invest Ophthalmol Visual Sci 1980; 17 (suppl): 179.

9 Campbell FW, Green DG. Optical and retinal factors affecting visual resolution. J Physiol 1965; 181: 576-95. 